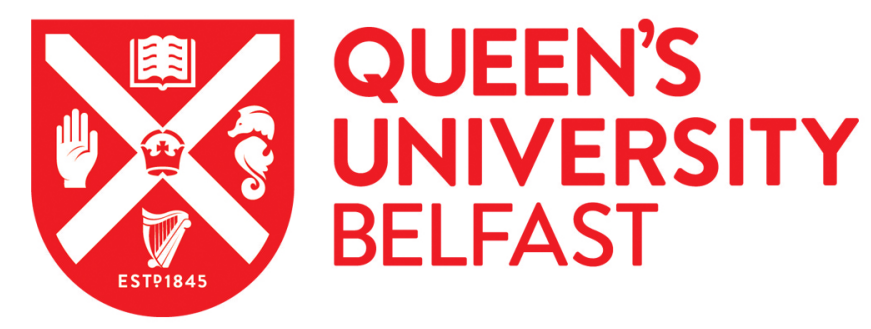

\title{
Experimental Investigation of Strain Sensitivity for Surface Bonded Fibre Optic Sensors
}

\author{
Motwani, P., Perogamvros, N., Taylor, S., Sonebi, M., Laskar, A., \& Murphy, A. (2020). Experimental \\ Investigation of Strain Sensitivity for Surface Bonded Fibre Optic Sensors. Sensors and Actuators A: Physical, \\ 303, [111833]. https://doi.org/10.1016/j.sna.2020.111833
}

\section{Published in:}

Sensors and Actuators A: Physical

\section{Document Version:}

Peer reviewed version

Queen's University Belfast - Research Portal:

Link to publication record in Queen's University Belfast Research Portal

\section{Publisher rights}

Copyright 2020 Elsevier Ltd.

This manuscript is distributed under a Creative Commons Attribution-NonCommercial-NoDerivs License

(https://creativecommons.org/licenses/by-nc-nd/4.0/), which permits distribution and reproduction for non-commercial purposes, provided the author and source are cited.

\section{General rights}

Copyright for the publications made accessible via the Queen's University Belfast Research Portal is retained by the author(s) and / or other copyright owners and it is a condition of accessing these publications that users recognise and abide by the legal requirements associated with these rights.

Take down policy

The Research Portal is Queen's institutional repository that provides access to Queen's research output. Every effort has been made to ensure that content in the Research Portal does not infringe any person's rights, or applicable UK laws. If you discover content in the Research Portal that you believe breaches copyright or violates any law, please contact openaccess@qub.ac.uk. 


\title{
Experimental Investigation of Strain Sensitivity for Surface Bonded Fibre Optic Sensors
}

\author{
P. Motwani ${ }^{1,2}$, N. Perogamvros ${ }^{1,3,4, *}$, S. Taylor ${ }^{1}$, M. Sonebi ${ }^{1}$, A. Laskar ${ }^{2}$, A. Murphy ${ }^{3}$ \\ 'School of Natural and Built Environment, Queen's University Belfast, Belfast, BT9 5AG, UK. \\ 2 Indian Institute of Technology Bombay, Mumbai, 400076, India. \\ ${ }^{3}$ School of Mechanical and Aerospace Engineering, Queen's University Belfast, Belfast BT9 5AH, UK. \\ ${ }^{4}$ Northern Ireland Advanced Composites and Engineering Centre, Belfast BT3 9DZ, UK.
}

\begin{abstract}
The strain sensitivity coefficient for a surface-mounted fibre optic sensor is strongly affected by the type of adhesive material used for its installation. In the present study, appropriate strain correction factors have been investigated to modify the strain sensitivity coefficient for surface mounted fibre Bragg gratings to achieve accurate strain data. The experimental study adopts a fibre optic sensor (FOS) mounted on a carbon fibre reinforced polyphenylene sulphide specimen using two adhesive types, i.e. a cyanoacrylate and an epoxy-resin. For comparison purposes strain data was also captured using strain gauge, contact extensometer and digital image correlation instrumentation. The experiments reveal that the predicted correction factors vary considerably with the adhesive material used for the mounting of the FOS. Further analysis demonstrates that a $37 \%$ deviation in the value of the correction factor results in a $27 \%$ variation in the strain output. In addition, the microscopic image analysis confirmed that the thickness of the adhesive layer between FOS and the substrate affects the strain sensitivity of FOS and plays a crucial role in transmitting the deformation of the host material to the sensing element.
\end{abstract}

Keywords: Fibre Bragg grating, Strain sensitivity coefficient, Carbon fibre composites, Adhesives, Microscopic image analysis

\subsection{Introduction}

Recently fibre-reinforced composite materials have been extensively used in advanced engineering structures, replacing homogeneous conventional materials (e.g. metal alloys). This is due to their superior strength and stiffness as well as their corrosion and fatigue resistant properties. However, the complicated degradation mechanisms and complex failure behaviour of composite materials tend to limit their usage within primary

\footnotetext{
* Corresponding author. Email address: n.perogamvros@qub.ac.uk. Tel. no.: +44 2890976672.
} 
structural components. This weakness has driven much research into structural health or condition monitoring for composite structures. Structural health monitoring (SHM) aims to monitor the behaviour of structures, detect damage, estimate current health status of the structure and even predict future failure during service [Fernando et al. (2003), Zhang et al. (2006), Moyo et al. (2005)]. The most widely investigated SHM technique is the fibre optic sensing approach. This is due to a number of favourable characteristics, including immunity to electromagnetic fields, multiplexing capability, linear response, and potential for embedment into structural systems [Merzbacher et al. (1996), Ansari (1997)]. The use of fibre Bragg grating (FBG) based fibre optic sensing has already been shown to be reliable and stable with time for observing structural behaviour [Chung et al. (2008)]. These sensors can have multiple sensing areas written on a single fibre line and can be interrogated from either end of the sensor. An FBG sensor reflects a peculiar wavelength of light, known as the Bragg wavelength, and transmits all others [Biswas et al. (2010)]. The conversion of the optical wavelength into mechanical strains is rather complex and is explained below.

\subsection{Theory of Fibre Bragg Grating}

The reflected wavelength (Bragg wavelength), represented here as $\lambda_{B I}$, satisfies Eq. 1 . A change in the initial grating period $\left(\Delta_{I}\right)$ and/or in the designed refractive index $\left(n_{e f f, I}\right)$, due to external influences (primarily strain and temperature), results in a shift of the reflected wavelength $\left(\Delta \lambda_{B I}\right)$, shown in Eq. 2 . Herein the focus is on the dependence of $\lambda_{B I}$ on strain and thus all experiments have been performed at a constant temperature (room temperature).

$\lambda_{B I}=2 \eta_{e f f, I} \Delta_{I}$

Eq. 1

$\frac{\Delta \lambda_{B I}\left(\varepsilon_{c}\right)}{\lambda_{B I}}=\frac{\partial \Delta_{I}\left(\varepsilon_{c}\right)}{\Delta_{I}}+\frac{\partial \eta_{e f f, I}\left(\varepsilon_{c}\right)}{\eta_{e f f, I}}$

The change in initial grating period $\left(\partial \Delta_{\mathrm{I}}\left(\varepsilon_{\mathrm{c}}\right)\right)$ is proportional to the applied strain; however, the response of the change in refractive index $\left(\partial n_{\text {eff,I }}\left(\varepsilon_{\mathrm{c}}\right)\right)$ is more complex. It is sensitive to both longitudinal strains as well as transverse and shear strains generated due to the Poisson's effect which result in birefringence of the FBG sensor. This results in splitting of the Bragg condition into two separate equations, one corresponding to a slower transverse wave and the other corresponding to the wave along the fast optic axis. Sirkis (1993) obtained the shift in the reflected wavelength of a FBG sensor considering pure axial loads on a free fibre with isotropic 
properties without shear strains (Eq. 3). The effective strain-optic coefficient $\left(\rho_{\text {eff }}\right)$ and the strain sensitivity coefficient $\left(F_{g}\right)$ relates the shift in Bragg wavelength $\left(\Delta \lambda_{B I}\left(\varepsilon_{c}\right)\right)$ to the strains within the FOS core $\left(\varepsilon_{c}\right)$. The relationship is dependent on the Pockel's constant $\left(P_{i j}\right)$, Poisson's ratio $(v)$ and the designed refractive index of the FOS core $\left(n_{e f f ; I}\right) . P_{i j}$ relates $\varepsilon_{c}$ with $n_{\text {eff; }}$ of the material where $\mathrm{i}$ and $\mathrm{j}$ represents the direction and plane of the strain tensor. For isotropic solids, $P_{i j}$ reduces to only two independent values which are $P_{11}$ and $P_{12}$ [Chen (2007)].

$$
\begin{aligned}
& \frac{\Delta \lambda_{B I}\left(\varepsilon_{c}\right)}{\lambda_{B I}}=\left(1-\frac{1}{2} n_{e f f, I}^{2}\left[P_{12}-v\left(P_{11}+P_{12}\right)\right]\right) \varepsilon_{c}=\left(1-\rho_{e f f}\right) \varepsilon_{c}=F_{g} \varepsilon_{c} \\
& F_{g}=\left(1-\frac{1}{2} n_{e f f, I}^{2}\left[P_{12}-v\left(P_{11}+P_{12}\right)\right]\right)
\end{aligned}
$$

The above procedure to estimate the strain sensitivity has been obtained for a bare or free fibre and is thus independent of any transfer mechanism from a host material or substrate. Based on this process, some sensor manufacturers report 'typical values' of $F_{g}$ based on the sensor construction technique. For instance, the typical values reported by Ivanov et al. (2002) for silica core materials are given in Table 1.

Table 1: Pockel's constant for silica core.

\begin{tabular}{lllll}
\hline Parameter & $P_{11}$ & $P_{12}$ & $v$ & $n_{\text {eff, I }}$ \\
\hline Value & 0.113 & 0.252 & 0.160 & 1.468 \\
\hline
\end{tabular}

Using Eq. $3 b$ and the values mentioned in Table $1, F_{g}$ can be calculated as $0.791 / \varepsilon_{c}$. However, the experimental value of $F_{g}$ is strongly dependent on both the sensor construction (mechanical properties of fibre core and protective layer) and also the connection to the host structure (i.e. adhesive layer properties) [(Ansari and Libo (1998)]. The connection to the host structure will thus affect the strain sensing capabilities of a FOS. Therefore, a more detailed analytical estimation of $F_{g}$, based on the stress transfer mechanism between a FOS and a host material is explained in the subsequent paragraphs. This is then followed by a more realistic determination of $F_{g}$ using experimental investigation.

Fig. 1 shows the normal and shear stresses acting on the various layers between FBG core and host material on which the FOS has been installed. 
The equilibrium of forces at the protective layer of the FOS in X-axis direction can be written as shown in Eq. 4, where, $r_{f c t}, r_{f c}$, and $r_{h}$ are the radius of the protective layer, fibre core and adhesive layer from the centre of the FOS, respectively. $\tau\left(x, r_{f c}\right)$ is the shearing stress at the interface between the fibre core and the protective layer, $\tau\left(x, r_{f c t}\right)$ is the shearing stress at the interface between the protective layer and the adhesive layer and $\tau\left(x, r_{h}\right)$ is the shearing stress at the interface between the adhesive layer and the host material at a distance $\mathrm{x}$ from the centre of the FOS. $\sigma_{f c}, \sigma_{f c t}, \sigma_{a}$ and $\sigma_{h}$ are the longitudinal stress in the fibre core, protective layer, adhesive layer and host material, respectively.

$\pi\left(r_{f c t}{ }^{2}-r_{f c}{ }^{2}\right) \sigma_{f c t}+2 \pi r_{f c} \int_{0}^{L_{f}} \tau\left(x, r_{f c}\right) d x-2 \pi r_{f c t} \int_{0}^{L_{f}} \tau\left(x, r_{f c t}\right) d x-2 \pi r_{h} \int_{0}^{L_{f}} \tau\left(x, r_{h}\right) d x=0$

Eq. 4 can be re-written as Eq. 5 and Eq. 6 incorporating the half-length of the FOS $\left(L_{f}\right)$.

$$
\begin{array}{ll}
\frac{1}{L_{f}} \int_{0}^{L_{f}} \pi\left(r_{f c t}{ }^{2}-r_{f c}{ }^{2}\right) \sigma_{f c t} d x+2 \pi r_{f c} \int_{0}^{L_{f}} \tau\left(x, r_{f c}\right) d x-2 \pi r_{f c t} \int_{0}^{L_{f}} \tau\left(x, r_{f c t}\right) d x-2 \pi r_{h} \int_{0}^{L_{f}} \tau\left(x, r_{h}\right) d x=0 & \text { Eq. } 5 \\
\frac{1}{L_{f}}\left(r_{f c t}{ }^{2}-r_{f c}{ }^{2}\right) \sigma_{f c t}+2 r_{f c} \tau\left(x, r_{f c}\right)-2 r_{f c t} \tau\left(x, r_{f c t}\right)-2 r_{h} \tau\left(x, r_{h}\right)=0 & \text { Eq. } 6
\end{array}
$$

Since the term $\left(r_{f c t}^{2}-r_{f c}^{2}\right)$ is comparatively smaller than the gauge length of the sensor $\left(2 L_{f}\right)$, the first term in Eq. 6 can be neglected to obtain the force equilibrium pertaining to the protective layer of the FOS as shown in Eq. 7.

$$
r_{f c} \tau\left(x, r_{f c}\right)=r_{f c t} \tau\left(x, r_{f c t}\right)+r_{h} \tau\left(x, r_{h}\right) \quad\left(\because L_{f}>>r_{f c t}^{2}-r_{f c}^{2}\right)
$$

Furthermore, the compatibility condition governing the axial deformation between the various interface layers can be represented as shown in Eq. 8, where, $\delta_{h}(x), \delta_{c}(x), \delta_{p}(x)$ and $\delta_{a}(x)$ are the axial deformation of the host material, fibre core, protective layer and adhesive layer, respectively.

$\delta_{h}(x)=\delta_{c}(x)+\delta_{p}(x)+\delta_{a}(x)$ Eq. 8 
It has been reported in a previous experimental study conducted by Ansari (1997) that the displacement in the host material results in the shear deformation of the protective layer and the adhesive material, while it generates axial displacement in the core material. Thus the displacements in the adhesive material, the protective material and the core material in Eq. 8 can be written as shown in Eqs. 9 to 11 .

$$
\begin{aligned}
& \delta_{p}(x)=\int_{r_{f c}}^{r_{f c t}} \gamma_{p}\left(x, r_{f c t}\right) d r=\int_{r_{f c}}^{r_{f c t}} \frac{\tau\left(x, r_{f c t}\right)}{G_{p}} d r \\
& \delta_{c}(x)=\int_{0}^{x} \varepsilon_{c}(x) d x=\int_{0}^{x} \frac{\sigma_{c}(x)}{E_{c}} d x=\frac{1}{E_{c} \pi r_{f c}^{2}} \int_{0}^{x} F_{f c} d x \\
& \delta_{a}(x)=\int_{r_{f c t}}^{r_{h}} \gamma_{a}\left(x, r_{h}\right) d r=\int_{r_{f c t}}^{r_{h}} \frac{\tau\left(x, r_{h}\right)}{G_{a}} d r
\end{aligned}
$$

Where, $\gamma_{p}\left(x, r_{f c t}\right)$ and $\gamma_{a}\left(x, r_{h}\right)$ is the shear strain pertaining to the protective layer and adhesive layer at a distance x from the centre of the FOS, respectively. $G_{p}$ and $G_{a}$ are the shear modulus of the protective layer and adhesive layer, respectively. $E_{c}$ represents the Young's Modulus of the fibre core and $F_{f c}$ is the axial force in the fibre core.

The deformation of the host material can be obtained from the deformation of the core, the protective layer and the adhesive layer by substituting Eqs. 9 to 11 in Eq. 8, as shown in Eq. 12.

$$
\delta_{h}(x)=\frac{1}{E_{c} \pi r_{f c}^{2}} \int_{0}^{x} F_{f c} d x+\int_{r_{f c}}^{r_{f c t}} \frac{\tau\left(x, r_{f c t}\right)}{G_{p}} d r+\int_{r_{f c t}}^{r_{h}} \frac{\tau\left(x, r_{h}\right)}{G_{a}} d r
$$

Ansari and Libo (1998) neglected the contribution of the adhesive layer and established a differential equation (Eqs. 13 and 14) for shear stress distribution between FBG core, protective layer and host material based on the deformation compatibility (Eq. 12) and force equilibrium (Eq. 7).

$$
\frac{d^{2} \tau\left(x, r_{f c}\right)}{d x}-k_{l}^{2} \tau\left(x, r_{f c}\right)=0
$$

Where, $k_{l}$ is the shear-lag coefficient and can be obtained using Eq. 14 . 


$$
k_{l}^{2}=\frac{2 G_{p}}{r_{f c}^{2} E_{c} \ln \left(\frac{r_{h}}{r_{f c}}\right)}
$$

Ansari and Libo (1998) solved the above ordinary differential equation using boundary conditions given in Eq. 15. The structural strains along the loading direction in the host material $\left(\varepsilon_{h}\right)$ can thus be obtained from the FBG core strains $\left(\varepsilon_{c}\right)$ using Eq. 16.

$$
\begin{aligned}
& F_{f c}(0)=\pi r_{f c}^{2} \sigma_{f c} \\
& F_{f c}\left(L_{f}\right)=0 \\
& \varepsilon_{h}=F_{g}\left(k_{l}, L_{f}\right) \varepsilon_{c} \\
& F_{g}\left(k_{l}, L_{f}\right)=\left[1-\frac{\cosh \left(k_{l} L_{f}\right)}{k_{l} L_{f} \sinh \left(k_{l} L_{f}\right)}\right]
\end{aligned}
$$

Zhao et al. (2012) developed Eqs. 17a and 17b in order to predict the strain transfer relationship (in terms of $F_{g}$ ) between the fibre core and the host material. The differential equation (Eq. 13) was solved considering separate Young's Modulus properties for the adhesive layer $\left(E_{a}\right)$, the fibre core $\left(E_{c}\right)$ and the protective coating $\left(E_{p}\right)$. It was observed that the width of adhesive layer $(W)$ and $E_{a}$ are the most critical parameters in determining the value of $F_{g}$ whereas the Poisson's ratio of the adhesive layer does not affect the value of $F_{g}$ significantly. It was also reported that a small change in $E_{a}$ results in significant fluctuations in $F_{g}$, thereby causing high variations in the strain output from an FBG sensor.

$$
\begin{aligned}
& k_{l}=\sqrt{\frac{W G_{a}}{\left(r_{h}-r_{f c}\right)\left\{2 \pi r_{f c}{ }^{2} E_{c}+\pi\left(r_{f c}{ }^{2}-r_{f c t}{ }^{2}\right) E_{p}+\left[W\left(h_{a}+r_{f c t}+\frac{r_{f c t}}{2}+\frac{r_{h}}{2}\right)-\pi r_{f c t}{ }^{2}\right] E_{a}\right\}}} \\
& F_{g}=1-\frac{1}{\operatorname{Cosh}\left(k_{l} L_{f}\right)}
\end{aligned}
$$

Li et al. (2016) proposed a similar theoretical model (Eqs. 18a and 18b) to predict the strain transfer relationship between an aluminium host material (Al 7075-T6) and a FOS mounted using an organic and metal welding adhesive layer. A single value of Young's Modulus $\left(E_{f}\right)$ was used for the FOS including both the fibre core and protective coating as a single entity. Due consideration was given to the transverse strain by including 
Poisson's ratio of the adhesive layer $\left(\mu_{b}\right)$ in the proposed model. Test results reported that the average $F_{g}$ value for the metal welding adhesive layer was 0.9912 in comparison to 0.9528 for the case of the epoxy resin.

$$
\begin{aligned}
& k_{l}^{2}=\frac{W E_{a}}{\left.2 \pi r_{f c t}{ }^{2} E_{f}\left(r_{h}-r_{f c t}\right)\left(1+\mu_{b}\right)\right)} \\
& F_{g}=1-\frac{\operatorname{Sinh}\left(k_{l} L_{f}\right)}{k_{l} L_{f} \operatorname{Cosh}\left(k_{l} L_{f}\right)}
\end{aligned}
$$

In summary, the parameters related to the FOS $\left(r_{f c}, r_{f c t}, E_{c}, E_{p}\right.$ and $\left.G_{p}\right)$ and the host material are typically available (in the case of the FOS from the manufacturer). However the properties related to the adhesive layer $\left(h_{a}\right.$ and $W$ ) are not readily available. Hence researchers have experimentally investigated the $F_{g}$ value for free un-bonded FBG strain sensors in the past [Boccaccio et al. (2010) and Roths and Julich (2008)] by calibrating the strains obtained from a FBG sensor against known applied strain values. These results, although theoretically correct, will not represent the test specimen installation and the full characteristics of the host material when subjected to deformations and strains. As a result, $F_{g}$ values retrieved through un-bonded FOS calibrations typically over-estimate the real strain values. A brief summary of $F_{g}$ values reported by various researchers through experimental and analytical investigations are presented in Table 2.

Table 2: Summary of analytical and experimental $F_{g}$ values reported in the corresponding literature.

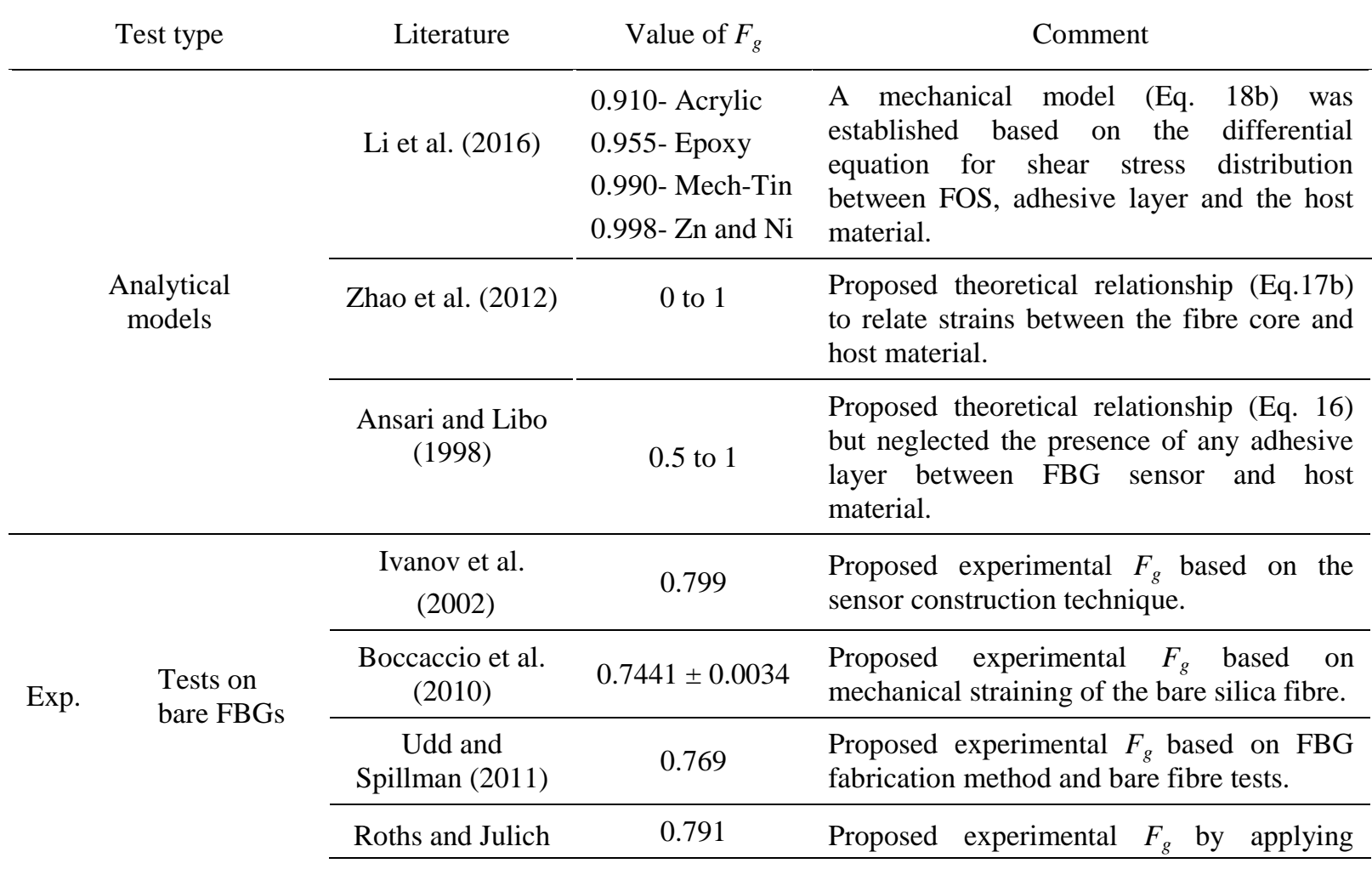




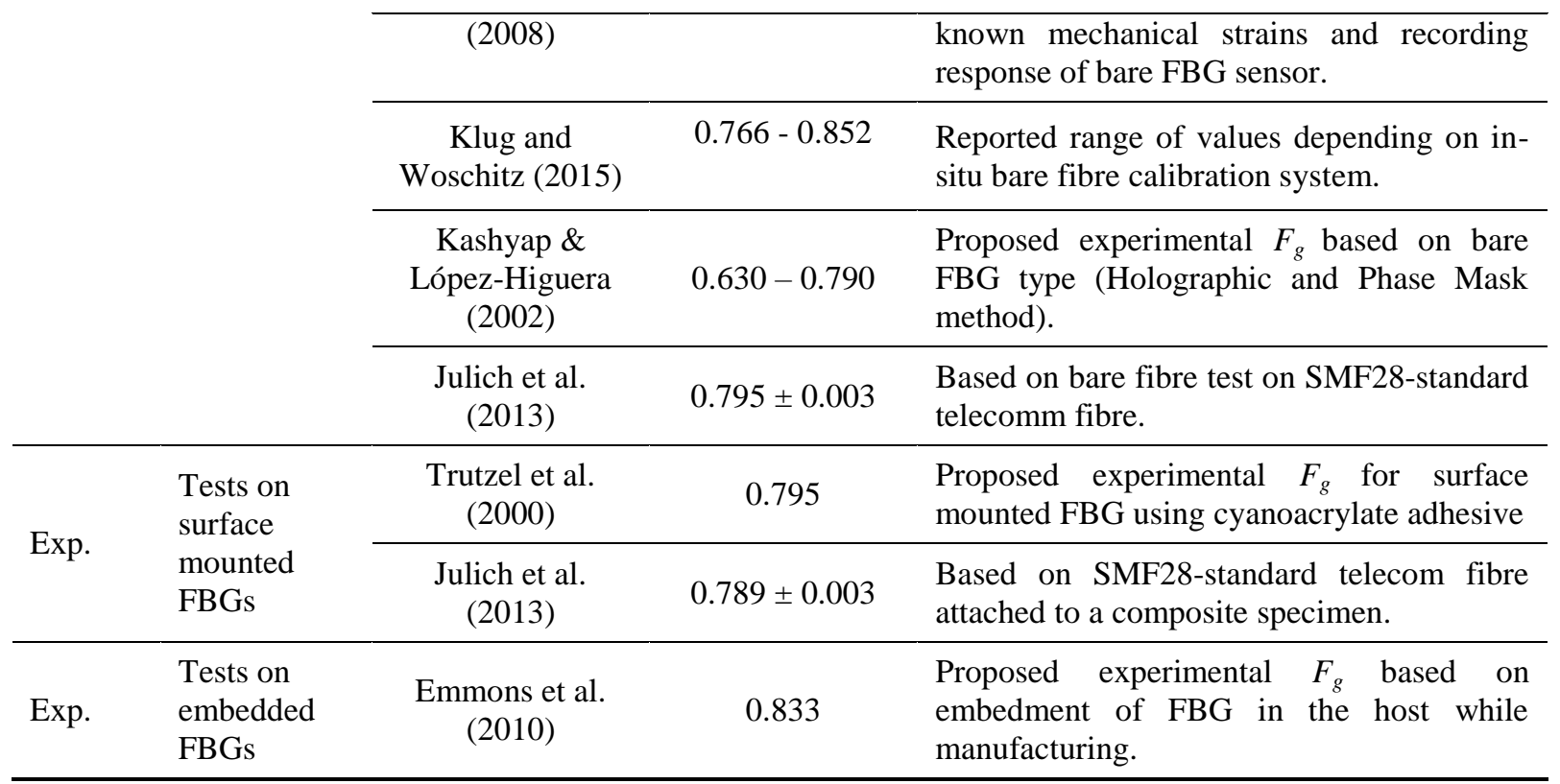

\subsection{Research Significance}

It can be observed from Table 2 that many experimental works ignore the contribution of the installation parameters. Additionally, the majority of the previous experimental works (Table 2) are available on lowviscosity adhesives, while very limited data is available on high-viscosity bonding agents for FOS installation. Thus, the aim of the present research is to:

1) experimentally estimate the $F_{g}$ values of surface mounted FBG sensors on a carbon fibre composite material, installed using a high and low-viscosity adhesive, and,

2) calibrate FBG sensors with standard strain measurement techniques to determine correction factors for the manufacturer's reported $F_{g}$ value.

It is important to mention that the terms 'low' and 'high' when describing adhesive viscosity are commonly used to characterize glues at room temperature with absolute viscosity values: 'low' viscosity adhesives are typically characterised by manufacturers in the range of $1-80$ centipoise $(\mathrm{cP})$ or $\mathrm{mPa} \cdot \mathrm{s}$, 'high' viscosity adhesives are typically characterised with viscosity values greater than $200 \mathrm{cP}$.

\subsection{Experimental Investigation}

\subsection{Test Specimen}

The carbon fibre reinforced Polyphenylene Sulphide (PPS) composite material, commercially known as $\mathrm{CETEX}^{\mathrm{TM}}$, was selected in the present study to prepare three identical flat tensile specimens (denoted as A, B and C in the current work), which conform to the ASTM Standard recommendations [ASTM D3039 (2006)]. 
Appropriate metal tabs were pasted at the ends of each coupon to prevent stress concentrations and possible premature failures. The nominal dimensions of a representative sample are summarized in Table 3.

Table 3: Dimensions of a representative test specimen.

\begin{tabular}{ll}
\hline Parameter & Dimension $(\mathrm{mm})$ \\
\hline Width of the specimen & 25 \\
Thickness of the specimen & 2.4 \\
Overall length of the specimen & 180 \\
Width of the tab & 25 \\
Length of the tab & 25 \\
Tab thickness & 1.5 \\
\hline
\end{tabular}

\subsection{Test Setup}

Uniaxial tensile loading was applied to the specimens with the aid of an accurately calibrated universal testing machine with a capacity of $100 \mathrm{kN}$, by gripping both the ends of each sample with wedge grips and serrated jaws (Fig. 2). The strain was induced to the specimen at an approximate rate of $0.01 \mathrm{~min}^{-1}$ [ASTM D3039 (2006)]. Both the load and displacement values were recorded at an acquisition rate of $100 \mathrm{~Hz}$. The same sampling rate was also adopted for the electrical resistance strain gauges and FOS presented in the following sections. A set of thermocouples were employed to monitor the temperature variations throughout the test duration in order to ensure that the experiments were conducted at a constant (room) temperature.

\subsection{Instrumentation}

\subsubsection{Extensometer and Strain Gauge}

In order to obtain the reference strain values, traditional methods for strain measurements, i.e. electrical resistance strain gauges (ERSGs) and extensometers, have been used during the experiments. ERSGs with an electrical resistance of $120 \mathrm{Ohm}$ and a gauge length of $5 \mathrm{~mm}$ were mounted on the composite samples utilizing a cyanoacrylate $(\mathrm{CN})$ adhesive; further details of this low viscosity adhesive are provided in the following section. The installation was performed following the guidelines proposed by several strain gauge manufacturers (e.g. HBM, Vishay, TML, etc.). In particular, the specimen surface at the gauge area was initially roughened and cleaned using emery paper (P320) and isopropyl alcohol, respectively. Then, the specimen was marked for alignment purposes and the strain gauge was placed and aligned at the cleaned area with the aid of cellophane tape. Afterwards, one end of the tape was lifted (including the strain gauge) and one drop of the $\mathrm{CN}$ adhesive 
was applied over the revealed grid length of the strain gauge. The tape was placed back, with the strain gauge at the aligned position, while a Teflon film (provided by the ERSG manufacturer) was positioned on the top of the tape and a distributed pressure was applied on this film for approximately $60 \mathrm{~s}$. Finally, after the curing of the $\mathrm{CN}$ adhesive, the cellophane tape was removed by peeling it back at an acute angle. After the above procedure, the thickness of the adhesive film in a correctly adhered strain gauge is around $8 \mu \mathrm{m}$, according to strain gauge manufacturers; the latter ensures the proper strain transfer from the host material to the strain gauge and, thus, the accurate calculation of the strain fields.

For the extensometer measurements, an initial gauge length of $20 \mathrm{~mm}$ was selected since the corresponding standard (ASTM D3039) suggests a range of $10 \mathrm{~mm}-50 \mathrm{~mm}$. In order to evaluate the performance of the FOS within the service strain range for SHM applications, the experiment in the present study has been performed only till $30 \%$ of the expected ultimate load of the carbon PPS specimen.

\subsubsection{Fibre Optic Sensors, Interrogator and Adhesive}

Three identical single-mode bend-insensitive silica-based FOS arrays, which encompass three FBGs each, with core and cladding diameters of $9 \mu \mathrm{m}$ and $125 \mu \mathrm{m}$, respectively, were employed in the current study. The thickness of the polyamide protective coating was $15 \mu \mathrm{m}$, resulting in an outer diameter of $155 \mu \mathrm{m}$ for the FOS (see also Fig. 4). The FBGs were written over a gauge length of $5 \mathrm{~mm}$ on a Boron doped photosensitive fibre (PS1250/1500) using phase mask technology with an operating wavelength range of 1510-1650 nm. The FBGs were designed for Bragg wavelengths based on the spectral range of the interrogation system and to prevent overlapping of Bragg wavelengths between two subsequent FBG gratings during tensile loading. The nomenclature used and the corresponding Bragg wavelengths of the individual FBG sensors are shown in Table

4. In order to assess the repeatability of the experimental results, a similar FBG arrangement was adopted for all tested specimens (A, B and C).

Table 4: Nomenclature, Bragg wavelength and adhesive characteristics for individual FBG sensors.

\begin{tabular}{cccccc}
\hline \multirow{2}{*}{ FBG No. } & FBG ID & $\begin{array}{c}\text { Adhesive thickness } \\
\left(h_{a}\right)\end{array}$ & \multicolumn{2}{c}{ Bragg wavelength $(\mathrm{nm})$} & Adhesive type \\
\cline { 4 - 5 } & & $=0$ & 1516.00 & 1517.68 & CN \\
\hline 1 & FBG1S & $>0$ & 1528.00 & 1528.21 & epoxy-resin \\
2 & FBG2S & $=0$ & 1540.00 & 1540.17 & epoxy-resin \\
\hline
\end{tabular}


A tuneable laser-based system (Micron Optics SM130) with an operating wavelength range of $1510 \mathrm{~nm}$ $1590 \mathrm{~nm}$ has been utilized in the present study to send the signal spectrum into the optical fibre. The wavelength uncertainty of the SM130 interrogator was stated by the manufacturer as $\sim 1 \mathrm{pm}$, leading to an uncertainty in the determination of $\lambda_{B I}$ of $\sim 0.1 \%$. A commercial code known as 'ENLIGHT ${ }^{\mathrm{TM}}$-Sensing Analysis Software' has been used for data acquisition, computation and analysis of the FOS output. ENLIGHT ${ }^{\mathrm{TM}}$ detects the reflected spectra from the FBG sensor and plots the Bragg wavelength by employing a least-square fitting routine for a parabolic function to the peaks of the reflected spectra. Fig. 3 shows the spectral section (solid blue line) that results in spectral peak (dashed vertical blue line) for each FBG detected along the FOS array. No birefringenceinduced peak splitting or deformations were observed after the installation of the FOS onto the carbon PPS specimen. The vertical axis in Fig. 3 represents the level of the reflected optical signal in 'Arbitrary Units (AU)'. AU in relation to FBG based sensors essentially represents a relative unit of measurement to show the ratio of intensity of the reflected Bragg wavelength to a predetermined reference measurement.

The carbon PPS specimen was prepared for FOS installation by sanding the specimen surface (P320) and cleaning with isopropyl alcohol. The sensor lines were drawn at either sides of the central portion of the gauge length. Typically, it is a strenuous task to handle an optical sensor with bare hands, due to their relatively small diameter and highly fragile nature, which can cause breakages. Thus, the FBGs were placed in position with slight tension and stabilized using tape strips before the application of the adhesive material, without touching directly the FBG sensing areas with fingers. As previously mentioned, the measurement accuracy of a surfacebonded FBG is strongly dependent on the type of adhesive material utilized and the mounting procedure adopted. Thus, it is pivotal to select an appropriate adhesive material in order to mount the FBG on the test specimen. The adhesive must be compliant enough to allow correct positioning of the FOS on the surface and stiff enough to ensure that the strains are accurately transferred from the host to the sensor. According to several FOS manufacturers, the cyanoacrylate adhesives (typically utilized for bonding strain gauges) are adequate to install FBGs on metallic and plastic materials. As a result, the $\mathrm{CN}$ adhesive, which was used to bond the electrical resistance strain gauges, was also used to install sensor FBG1S over the central gauge region of the carbon PPS specimens (Fig. 4). The adopted CN glue has low viscosity ( $20 \mathrm{cP}$ at room temperature) and requires approximately one minute to form its functional strength; however, curing continues for $24 \mathrm{~h}$, depending on the ambient temperature and humidity conditions, before full chemical resistance is developed. Nevertheless, its continuous contact with water results in the disruption of the chemical bond between the $\mathrm{CN}$ adhesive and the substrate material. Therefore, for comparison purposes and aiming to find a suitable alternative 
to the $\mathrm{CN}$ adhesive, a strong, long lasting, solvent-free adhesive (commercially known as 'Araldite® Rapid 2Part Epoxy') was used as the epoxy-resin glue in the present study. Araldite $\AA$ is a high viscosity $(\sim 25000 \mathrm{cP}$ at room temperature) adhesive which allows 4 min of working time and sets in 20 min, while it attains full strength within two hours of curing. In addition, this epoxy-resin adhesive is more durable and water resistant than $\mathrm{CN}$ adhesives when subjected to aggressive environment [Luoma and Rowland (1986)].

As previously noted, FBG1S was installed using the CN adhesive, while sensors FBG2S and FBG3S were installed using epoxy-resin. For the case of FBG1S, a procedure similar to the one reported for the ERSG installation (see also section 2.3.1) was adopted for mounting the sensors on the composite specimens; this mounting technique ensures an adhesive layer with an almost zero thickness $\left(h_{a}\right)$ value. On the other hand, the FBG2S and FBG3S sensors, which were installed using the epoxy-resin glue, were mounted on the specimens without applying any pressure over the sensor area. Instead, cellophane tape strips were used to stabilise the sensor at the gauge region allowing a window at the location of the sensing area; then, the epoxy-resin was simply poured over this window and allowed to cure for $24 \mathrm{~h}$. It is important to mention that sensor FBG2S was bonded intentionally with a non-zero $h_{a}$ value, while sensor FBG3S was installed in such a way to ensure a zero value for the $h_{a}$ parameter; this was achieved by changing the distance between the tape strips applied next to the gauge area for stabilization purposes. Furthermore, it should be noted that the aforementioned technique resulted in different non-zero $h_{a}$ values for the FBG2S sensors in each of the three specimens (A, B and C); however, the resulting non-zero $h_{a}$ range was identified with the aid of a post test optical microscopy study, presented in section 3.4. The adhesive type and thickness group for each FBG sensor are tabulated in Table 4, while the layout of the FOS array along with the three FBG strain sensors mounted on the carbon PPS specimens are schematically depicted in Fig. 4.

A noteworthy observation during the installation of the FOS is the small change in the initially designed Bragg wavelengths, as reported in Table 4. This wavelength shift can be mainly attributed to adhesive installation and curing period. The effect of any pre-strain appeared to be negligible since the readings taken just before the application of glue (but after stabilizing the sensor on the specimen) did not show any noticeable wavelength change. It can also be noted that the Bragg wavelength of sensors FBG2S and FBG3S installed using the epoxy-resin were not significantly affected by the installation procedure since epoxy adhesives provides higher flexibility and longer working time than the $\mathrm{CN}$ adhesive.

\subsubsection{Digital Image Correlation Setup}


The digital image correlation (DIC) technique involves the measurement of displacement/deformation up to an accuracy of $0.005 \mathrm{~mm}$ [Pan et al. (2009)] by tracking the position of multiple points on a virtual grid surface on the specimen using two consecutive camera images with a correlation algorithm [Chu et al. (1985)]. In the current work the DIC was essentially used as an independent measurement technique to verify and compare the readings from the strain gauges. The Q-400 DIC system by Dantec Dynamics was used in the present study. The specimen was painted with white followed by black paint in order to create a random speckle pattern on the host material for successful correlation between the two images of the DIC camera. It has been ensured that the speckles do not exhibit a bias to any orientation or surface and are highly contrasted. Fig. 5a shows the camera image of the speckle pattern applied on an area of $25 \times 25 \mathrm{~mm}$ over the gauge region of the composite specimen.

Furthermore, a smooth white light was placed close to the specimen in order to eliminate the effects of the change in the natural lighting on the specimen. Initial calibration of the DIC system has been performed before analysing the specimen for strains and displacement. This has been done in order to obtain the imaging parameters like coordinate system, lighting, as well as the orientation and position of one camera with respect to the other. The calibration parameters have been evaluated by estimating the residuum value using the DIC algorithm. The residuum value should be less than 0.1 to ensure that the DIC has accurately recorded the intrinsic and extrinsic parameters describing the image of the calibration target. Three reference images were taken before the application of any load to the composite specimen, thereafter, images of the composite specimen were taken at an acquisition rate of $1 \mathrm{~Hz}$ during the measurement process. Subsequently, ISTRA-4D commercial code was utilised to apply the correlation algorithm for the quantitative data evaluation of the test images.

\subsection{Results and Discussion}

\subsection{Verification of ERSG Readings with DIC Measurements}

Prior to the assessment of the ERSG readings using the strain fields extracted from the DIC technique, an analysis of the results from the latter technique is performed. The recorded digital images were smoothed to remove the noise using ISTRA-4D code to obtain full field displacement and strain maps. Fig. 5b shows the contour plot for the best fit plane (BFP) obtained through DIC. It can be seen that the DIC technique is able to capture the protrusion at the centre of the host material which represents the FBG3S location mounted using the high viscosity epoxy resin (refer to Fig. 4). It can be understood that the DIC measurements without the 
presence of FOS would better reveal the pure host material behaviour. Hence two gauge points defined over the region of interest (ROI) were investigated to compare the strains over the substrate material and over FBG3S sensor. The change in engineering strain values over the loading duration at the two gauge points are shown in Fig. 6.

In Fig. 6 it can be seen that the strains on the FBG region are slightly higher than the strains recorded directly on the substrate material. This difference in the observed behaviour is presumably due to an additional strain transfer layer (adhesive material) that exists between the FBG sensor and the substrate material. It could also be attributed to the minor variations in the grid pattern formed by the DIC algorithm due to the protrusion of the host material at the sensor location, which can be visualized from the BFP plot shown previously in Fig. 5b. However, the discrepancies presented between the two curves in Fig. 6 are less than $2 \%$ in terms of peak strain values, thus the strains measured on the FBG sensor can be used for the verification purposes.

The similar strain outputs can also be observed in Fig. 7a. The latter figure illustrates the longitudinal (yaxis) DIC strain map at the specimen's gauge region when the maximum load is applied during the experiment; it can be seen that the contour of the surface strains presents an almost uniform pattern over the entire ROI, where all sensing elements are placed. The nearly homogeneous strain fields developed allow the direct comparison of the data extracted from the various sensors located along the different line segments in the ROI (Fig. 7a). It is important to note that textile composites, as the one employed in this study, commonly reveal heterogeneous surface strain fields with highly localized strain concentrations; however, under longitudinal loading and for small strain levels (i.e. less than $0.5 \%$ ) the contour of surface strains remains nearly uniform [Daggumati et al. (2011), del Rey Castillo et al. (2019)], as it is also presented in Fig. 7a.

Fig. 7b presents strain versus time curves obtained from the DIC and ERSG measurements for specimen A; both curves are in very good agreement, showing a deviation of around 3\% with respect to the peak strain data. Therefore, strain gauge readings extracted from the ERSGs, which are mounted at the gauge region of the tensile specimens, were used for all subsequent analysis.

\subsection{Estimation of FBG Strain Sensitivity Coefficient and Correction Factor}

The strains obtained from the strain gauges were used as the reference values for the estimation of the sensitivity coefficient of the FBG sensors installed on the tensile coupons. In Fig. 8 the relative shift in Bragg wavelength due to the mechanical strains obtained from the individual FBG sensors has been plotted versus the strains obtained through the ERSG for all three specimens. As it can be observed from these plots the shift in Bragg 
wavelength for the FBG1S and FBG3S sensors are linearly proportional to the tensile strain obtained from the ERSGs. However, the shift in Bragg wavelength from the FBG2S sensors (red curves in Fig. 8) was not proportional to the tensile strain measured using the ERSGs. This non-linear behaviour can be attributed to the thick adhesive layer between the sensor and the host material, since FBG2S was bonded with $h_{a}>0$; further details regarding this response are provided in section 3.4.

The strain correlation coefficient $\left(k_{g}\right)$, which is obtained as the slope of the best-fit curve between the shift of FBG Bragg wavelengths and ERSG strains (Fig. 8), is tabulated in Table 5. As can be noted in the latter table, the $F_{g}$ values (inverse of $k_{g}$ ) obtained from the present experimental studies for FBG1S sensors mounted using low viscosity $\mathrm{CN}$ adhesive is close to the $F_{g}$ value of 0.833 , reported by the manufacturer, which is obtained from a bare fibre test. However, considerable differences can be observed in the $F_{g}$ values calculated for the FBG2S and FBG3S sensors installed using high viscosity adhesive (epoxy-resin). Thus, it can be concluded that although $F_{g}$ is primarily based on the sensor construction technique, it is also strongly affected by the type of adhesive material used for the application of FOS on the host specimen.

Table 5: Experimental values for $k_{g}$ and $F_{g}$; proposed strain correction factors $\left(k_{c}\right)$.

\begin{tabular}{|c|c|c|c|c|c|}
\hline \multirow[b]{2}{*}{ Specimen } & \multirow[b]{2}{*}{ Sensor } & \multirow[b]{2}{*}{$k_{g}\left(\times 10^{-4} \mu \varepsilon^{-1}\right)$} & \multicolumn{2}{|c|}{$F_{g}$} & \multirow[b]{2}{*}{$k_{c}$} \\
\hline & & & $\begin{array}{c}\text { Manufacturer } \\
\text { reported }\end{array}$ & Experiment & \\
\hline \multirow{3}{*}{ A } & A-FBG1S & 1.2235 & \multirow{3}{*}{0.833} & 0.813 & 0.975 \\
\hline & A-FBG2S & 2.8594 & & 0.350 & 0.420 \\
\hline & A-FBG3S & 1.3892 & & 0.719 & 0.863 \\
\hline \multirow{3}{*}{ B } & B-FBG1S & 1.3571 & \multirow{3}{*}{0.833} & 0.737 & 0.885 \\
\hline & B-FBG2S & 51.773 & & 0.019 & 0.022 \\
\hline & B-FBG3S & 1.5071 & & 0.664 & 0.797 \\
\hline \multirow{3}{*}{$\mathrm{C}$} & C-FBG1S & 1.4619 & \multirow{3}{*}{0.833} & 0.684 & 0.821 \\
\hline & C-FBG2S & 30.459 & & 0.033 & 0.040 \\
\hline & C-FBG3S & 1.6868 & & 0.593 & 0.712 \\
\hline
\end{tabular}

In order to estimate the error in the strain output from all FBG sensors with the use of $F_{g}$ as 0.833 , Fig. 9 has been plotted to show the comparison of strain histories from FBG sensors and ERSG measurements. The plots in the left column of Fig. 9 (i.e. Fig. 9a, 9c and 9e) show the strain versus time relationship for specimens A, B and $\mathrm{C}$ obtained from FBG sensors with the use of the manufacturer's reported $F_{g}$ value of 0.833 . As expected, the majority of the FBG strain histories calculated using the latter $F_{g}$ value showed major discrepancies between the results obtained from FBG sensors and the ERSG data. 
The measured experimental data can be used to propose strain correction factors $\left(k_{c}\right)$ to the manufacturer's reported $F_{g}$ value in order to obtain more precise results for the strain output of the FBG sensors using the $\mathrm{CN}$ and the two component epoxy adhesives. In particular, corrected $F_{g}$ values were calculated for each FBG sensor by correlating the strain histories obtained from the strain gauge and the shift in Bragg wavelengths from the FOS. Subsequently, correction factors are proposed to the manufacturer's reported $F_{g}$ value for each adhesive type and adhesive thickness (Table 5). The data analysis and correlation of strains measured using strain gauges and FBG sensors revealed an average $k_{c}$ value of $0.893,0.161$ and 0.791 for the FBG1S, FBG2S and FBG3S sensors, respectively. Thus, the corrected average $F_{g}$ value for the FBG1S sensor mounted using $\mathrm{CN}$ adhesive and the FBG2S and FBG3S sensors mounted using two-component adhesive has been predicted as $0.745,0.134$ and 0.659 , respectively (see also Table 5). The averaged $k_{g}, F_{g}$, and $k_{c}$ values are summarized in Table 6. In addition, the plots in the right column of Fig. 9 (i.e. Fig. 9b, 9d and 9f) illustrate the strain versus time relationship for specimens $\mathrm{A}, \mathrm{B}$ and $\mathrm{C}$ obtained from FBG sensors with the use of the corrected $F_{g}$ values. From Fig. 9b, 9d and $9 \mathrm{f}$ it can be observed that there is practically no difference between the strains reported from ERSG, FBG1S and FBG3S. However, even with the use the calculated correction factors, the FBG2S sensor show major discrepancies when compared with strains obtained using other instrumentation. The reason for such high discrepancies of FBG2S sensor is discussed in section 3.4.

Table 6: Average $k_{g}, F_{g}$ and $k_{c}$ values calculated for individual FBG sensors

\begin{tabular}{ccccc}
\hline Sensor & Specimen & $k_{g}\left(\times 10^{-4} \mu \varepsilon^{-1}\right)$ & $F_{g}$ & $k_{c}$ \\
\hline FBG1S & A, B and C & 1.3475 & 0.745 & 0.893 \\
FBG2S & A, B and C & 28.3638 & 0.134 & 0.161 \\
FBG3S & A, B and C & 1.5277 & 0.659 & 0.791 \\
\hline
\end{tabular}

\subsection{Strain Sensitivity Analysis}

A sensitivity analysis has been performed on a representative sample (specimen A) to observe the responsiveness of the $F_{g}$ coefficient in converting the shift of the FBG Bragg wavelength to mechanical strains. The results presented in Fig. 10 and Table 7 shows the response of a selected correction factor to appropriately correct the manufacturer's reported $F_{g}$ value of FOS (which in the present case is 0.833 ) and, subsequently, predict the specimen strains. The vertical axis in Fig. 10 represents the peak strain values obtained from FBG sensors, ERSG, extensometer and DIC, while the horizontal axis shows the type of FBG sensor. Note that, in addition to DIC verification, the precision of the strain gauge data was also confirmed by extensometer readings. 
Since FBG2S showed erroneous results, it has been eliminated from the strain sensitivity studies and results for FBG1S and FBG3S sensors are only presented in Fig. 10. The filled symbols represent the choice of various $k_{c}$ values which have been selected based on the minimum and maximum value of $F_{g}$ reported in the experimental literature (Table 2).

From Table 7 it can be observed that the peak strains calculated, from sensor FBG1S, using the minimum (0.75) and maximum (1.03) $k_{c}$ values, results in a range of peak strains from $1788 \mu \varepsilon$ to $1310 \mu \varepsilon$. This indicates that a $37 \%$ deviation in $k_{c}$ (from 0.75 to 1.03 ) results in a $27 \%$ variation in strain value. Moreover, the peak strain of $1788 \mu \varepsilon$ from FBG1S using $k_{c}=0.75$ is a $31 \%$ over-estimation of the reference strain (i.e. $1367 \mu \varepsilon$ from ERSG data). This is in agreement with the observation reported by Hill and Meltz (1997) that a $25 \%$ variation in the strain sensitivity coefficients results in errors of several $100 \mu \mathrm{m} / \mathrm{m}$ in the measurement of the mechanical strains. The results from the current study further refines this observation by identifying and quantifying how sensor installation technique can affect the strain output from FBG sensors.

Table 7: Peak strains from auxiliary measuring techniques and FBG sensors using various $k_{c}$ values for a representative sample (specimen A).

\begin{tabular}{|c|c|c|c|c|c|c|}
\hline \multirow{2}{*}{\multicolumn{3}{|c|}{$\begin{array}{l}\text { Peak strain } \\
(\mu \mathrm{m} / \mathrm{m})\end{array}$}} & \multicolumn{4}{|c|}{ FBG Sensor } \\
\hline & & & \multirow[t]{2}{*}{$\begin{array}{l}\text { Manufacturer } \\
\text { reported } F_{g}\end{array}$} & \multirow[t]{2}{*}{$\begin{array}{c}\text { Selected } \\
k_{c}\end{array}$} & \multicolumn{2}{|c|}{$\begin{array}{l}\text { Peak strain from FBG } \\
\text { sensor with corrected } F_{g} \\
(\mu \mathrm{m} / \mathrm{m})\end{array}$} \\
\hline ERSG & DIC & Extensometer & & & FBG1S & FBG3S \\
\hline 1367 & 1410 & 1364 & 0.833 & $\begin{array}{l}0.75 \\
0.87 \\
1.00 \\
1.03\end{array}$ & $\begin{array}{l}1788 \\
1543 \\
1357 \\
1310\end{array}$ & $\begin{array}{l}1524 \\
1362 \\
1198 \\
1116\end{array}$ \\
\hline
\end{tabular}

\subsection{Microscopic Image Analysis}

Previously, Fig. 8 demonstrated a non-linear relationship between the shift in Bragg wavelength of sensor FBG2S and the ERSG data. This could be attributed to the installation technique used for the mounting of the FBG2S sensor, which resulted in a non-zero adhesive layer thickness $\left(h_{a}>0\right)$, as also described in section 2.3.2.

In order to gain a further insight into the above outcome and provide further details regarding $h_{a}$ values and poor readings of the FBG2S sensors, post mechanical test the specimens were prepared for microscopic observation. The specimens were cut at FBG location and cured with powdered resin; afterwards the examined surfaces were polished with fine emery paper in order to achieve a clear cross-section view (Fig. 11). Repetitive microscopic observation performed on the FBG2S sensor bonded on specimen A, revealed that the adhesive layer thickness between the host material and the FBG was $240 \mu \mathrm{m}$, while for the case of specimens B and C the 
$h_{a}$ values for FBG2S were $516 \mu \mathrm{m}$ and $465 \mu \mathrm{m}$, respectively. These thickness levels are probably too high to efficiently transfer the host material deflections to the FBG sensor (Fig. 11b). It is known that the strain transferred to an FBG sensor from the substrate through the bonding layer is smaller than the substrate's true strain [Li et al. (2010)]. This strain transmission loss is elevated when the bonding material is of low modulus compared to the substrate stiffness and the bonding layer thickness is large, as also presented in the current work. This strain lag can result in strain transmission rates which are non-constant at some deformation levels; thus the shift in the Bragg wavelength of a bonded FBG may result in a different rate of change compare to the rate of change of strain at the specimen's surface which, in the present investigation, is accurately extracted using the ERSG data. This is most likely the reason for the non-linear response (Fig. 8) and the considerable difference in the results observed from the FBG2S sensor, even when the calibrated correction factors were employed (Fig. 9). In the case of the FBG1S and FBG3S sensors installed using CN adhesive and epoxy-resin, respectively, it has been found that the mounting procedure adopted in the present study (see also section 2.3.2) was able to ensure complete contact between the sensor and the host material (Fig. 11a and Fig. 11c) resulting in proper strain measurement, as shown previously in Fig. 9. This indicates that the thickness of the adhesive layer plays a crucial role in determining the strain transfer mechanism between the host material and the FBG sensor. Thus, the present study recommends that the thickness of the adhesive layer should be minimised between the host material and FBG sensor by utilizing appropriate installation procedures.

\subsection{Comparison of Experimental and Analytical $F_{g}$ Values}

The experimentally extracted $F_{g}$ values after applying the appropriate correction factors have been compared with the analytical expressions proposed by Li et al. (2016) and Zhao et al. (2012) in Fig. 12. The individual symbols in the figure show the $F_{g}$ values with correction factors, while the lines with filled symbols depict the analytical predictions. Note that the mean values (Table 6) have been plotted for FBG1S and FBG3S sensors, while the FBG2S data are depicted separately for each specimen since different $h_{a}$ values were measured previously. The analytical trend, which provides data for $h_{a}=0$, indicates a strain transfer rate between the substrate and the FBG sensor of $100 \%$ (resulting in an $F_{g}$ value of 1) when the adhesive layer thickness is zero. However, the present experimental study reveals that even with $h_{a}$ equals to zero, a portion of strain is absorbed between the FOS core and the substrate material, possibly due to the presence of the FOS protective material and the adhesive portions next to the FOS/specimen contact point; thereby resulting in an $F_{g}$ value of less than 1. Additionally, the analytical trend shown in Fig. 12 reports that the magnitude of the strain absorbed by the 
adhesive layer is directly proportional to the thickness of the adhesive layer. This has been experimentally verified, since the increasing values of $h_{a}$ showed a decreasing trend of the transfer rate.

\subsection{Conclusions}

A comparison of the strains obtained from the standard instrumentation (ERSG, DIC and extensometer) and three FBG strain sensors has been conducted on a carbon PPS specimen tested under uniaxial tensile loading with the aid of an accurately calibrated tensile testing machine in laboratory controlled conditions. The FOS comprised a silica core and polyimide coating, and were attached to the specimen using a $\mathrm{CN}$ and a twocomponent epoxy adhesive. Based on the experimental study, the following conclusions have been drawn;

1) The results obtained from the FBG sensors when mounted using high viscosity two-component (epoxyresin) adhesive and the manufacturer's reported $F_{g}$ value demonstrated major discrepancies in comparison to reference data extracted from other measurement techniques (e.g. ERSG). For the case of the $\mathrm{CN}$ adhesive, FBG sensors showed better strain predictions; however, some noteworthy deviations still exist. Thus, it is imperative that a sensor in-situ calibration is conducted to determine the appropriate correction factors $\left(k_{c}\right)$ to be applied to the manufacturer's reported $F_{g}$ value, before utilizing a specific adhesive for sensor installation on actual structures.

2) High viscosity adhesive can be used for surface mounted FOS applications and can accurately replace the $\mathrm{CN}$ adhesive. However, the use of high-viscosity adhesive requires appropriate installation of the FBG sensor on the host material. Accurate strain data can be attained by ensuring minimum adhesive layer thickness between the FBG sensor and the substrate material.

The above conclusions are based on the experimental investigation performed solely on a carbon PPS specimen instrumented with a $155 \mu \mathrm{m}$ diameter FOS. Nevertheless, the method developed and outlined herein can be used to determine appropriate correction factors for other FOS, test specimens and adhesive material combinations.

\section{Acknowledgements}

The authors would like to acknowledge the support received from the commonwealth scholarship commission in the UK for providing necessary funding and resources. The authors would also like to acknowledge the support received from the Invest Northern Ireland Advanced Engineering Competence Centre (NIAECC) for providing necessary resources. 


\section{References}

ASTM Standard D3039, 2006, "Standard Test Method for Tensile Properties of Polymer Matrix Composite Materials.” ASTM International, West Conshohocken, PA.

Ansari, F. and Libo, Y. "Mechanics of Bond and Interface Shear Transfer in Optical Fibre Sensors." Journal of Engineering Mechanics, V. 124, N. 4, 1998, pp. 385-94.

Ansari, F. "State-of-the-art in the Applications of Fibre-Optic Sensors to Cementitious Composites." Cement and Concrete Composites, V. 19, N. 1, 1997, pp. 3-19.

Boccaccio, D. and Zoccoli, A. "Calibration of a Fibre Bragg Grating as Ultra-Sensitive Strain Gauge.” LNL Annual Report, Appl. Gen. and Interdisc. Phys. Instrumentation, 2010, pp. 191-192.

Biswas, P., Bandyopadhyay, S., Kesavan, K., Parivallal, S., Sundaram, A., Ravisankar, K. and Dasgupta, K. "Investigation on Packages of Fibre Bragg Grating for use as Embeddable Strain Sensor in Concrete Structure.” Sensors and Actuators A: Physical, V. 157, N. 1, 2010, pp. 77-83.

Chu, C., Ranson, F. and Sutton, A. "Applications of Digital-Image-Correlation Techniques to Experimental Mechanics." Experimental Mechanics, V. 25, N. 3, 1985, pp. 232-44.

Chen, C.L., "Foundations for Guided-Wave Optics." John Wiley \& Sons, 2007.

Chung, W., Kim, S., Kim, S. and Lee, U. "Deflection Estimation of a Full Scale Prestressed Concrete Girder using Long-Gauge Fibre Optic Sensors.” Construction and Building Materials, V. 22, N. 3, 2008, pp. 394-401.

Daggumati, S., Voet, E., Van Paepegem, W., Degrieck, J., Xu, J., Lomov, S. V. and Verpoest, I. "Local strain in a 5-harness satin weave composite under static tension: Part I - Experimental analysis.” Composites Science and Technology, V. 71, N. 8, 2011, pp. 1171-79.

del Rey Castillo, E., Allen, T., Henry, R., Griffith, M. and Ingham, J. "Digital image correlation (DIC) for measurement of strains and displacements in coarse, low volume-fraction FRP composites used in civil infrastructure." Composite Structures, V. 212, 2019, pp. 43-57.

Emmons, C., Karnani, S., Trono, S., Mohanchandra, P., Richards, L. and Carman, P. "Strain Measurement Validation of Embedded Fibre Bragg Gratings.” International Journal of Optomechatronics, V. 4, N. 1, 2010, pp. 22-33.

Fernando, F., Hameed, A., Winter, D., Tetlow, J., Leng, J., Barnes, R., Mays, G. and Kister, G. "Structural Integrity Monitoring of Concrete Structures via Optical Fibre Sensors: Sensor Protection Systems.” Structural Health Monitoring, V. 2, N. 2, 2003, pp. 123-35.

Hill, O. and Meltz, G. "Fibre Bragg Grating Technology Fundamentals and Overview." Journal of Lightwave Technology, V. 15, N. 8, 1997, pp. 1263-76.

Ivanov, S., Kravtsov, E. and Tikhomirov, V. "Problems of Metrological Support of Measurements in FibreOptic Transmission Systems.” In Proc. of SPIE, V. 4900, 2002.

Jülich, F., Aulbach, L., Wilfert, A., Kratzer, P., Kuttler, R. and Roths, J. “Gauge Factors of Fibre Bragg Grating Strain Sensors in different types of Optical Fibres.” Measurement Science and Technology, V. 24, N. 9, 2013, pp. 094007.

Klug, F. and Woschitz, H. "Test and Calibration of 20 FBG based Strain Transducers." In Proc. of SHMII VII, 2015, pp. 1-11. 
Kashyap, R. and López-Higuera, M. "Fibre Grating Technology: Theory, Photosensitivity, Fabrication and Characterization." Handbook of Optical Fibre Sensing Technology, John Wiley and Sons, 2002, pp. 349-377.

Li, W.Y., Cheng, C.C. and Lo, Y.L. "Investigation of strain transmission of surface-bonded FBGs used as strain sensors." Sensors and Actuators A: Physical, V. 149, N. 2, 2010, pp. 201-207.

Li, H., Zhu, L., Dong, M., Lou, X. and Guo, Y. “Analysis on Strain Transfer of Surface-Bonding FBG on Al 7075-T6 Alloy Host.” Optik-International Journal for Light and Electron Optics, V. 127, N. 3, 2016, pp. 1233-6.

Luoma, A and Rowland, D. "Environmental Degradation of an Epoxy Resin Matrix." Journal of Applied Polymer Science, V. 32, N. 7, 1986, pp. 5777-90.

Moyo, P., Brownjohn, M., Suresh, R. and Tjin, C. "Development of Fibre Bragg Grating Sensors for Monitoring Civil Infrastructure.” Engineering Structures, V. 27, N. 12, 2005, pp. 1828-34.

Merzbacher, I., Kersey, D. and Friebele, J. "Fibre Optic Sensors in Concrete Structures: A Review." Smart Materials and Structures, V. 5, 1996, pp. 196-208.

Pan, B., Qian, K., Xie, H. and Asundi, A. "Two-Dimensional Digital Image Correlation for In-Plane Displacement and Strain Measurement: A Review.” Measurement Science and Technology, V. 20, N. 6, 2009, pp. 062001.

Roths, J. and Jülich, F. “Determination of Strain Sensitivity of Free Fibre Bragg Gratings.” In Proc.of SPIE, V. 7003, 2008, pp. 700308.

Sirkis, J.S. "Unified Approach to Phase-Strain-Temperature Models for Smart Structure Interferometric Optical Fibre Sensors.” Part 2, Applications. Optical Engineering, V. 32, N. 4, 1993, pp. 762-74.

Trutzel, M., Wauer, K., Betz, D., Staudigel, L., Krumpholz, O., Muehlmann, H., Muellert, T. and Gleine, W. "Smart Sensing of Aviation Structures with Fibre Optic Bragg Grating Sensors." In Proc.of SPIE, V. 3986, 2000, pp. 134-143.

Udd, E. and Spillman, B. "Fibre Optic Sensors: An Introduction for Engineers and Scientists." John Wiley \& Sons, 2011.

Zhang, W., Gao, J., Shi, B., Cui, H. and Zhu, H. "Health Monitoring of Rehabilitated Concrete Bridges using Distributed Optical Fibre Sensing." Computer-Aided Civil and Infrastructure Engineering, V. 21, N. 6, 2006, pp. 411-24.

Zhao, T., Wang, B., Qiu, Y., Chen, A., Wang, Y. and Fan, M. "Strain Transfer of Surface-Bonded Fibre Bragg Grating Sensors for Airship Envelope Structural Health Monitoring.” Journal of Zhejiang University Science, V. 13, N. 7, 2012, pp. 538-45. 


\section{Figures}

(a)

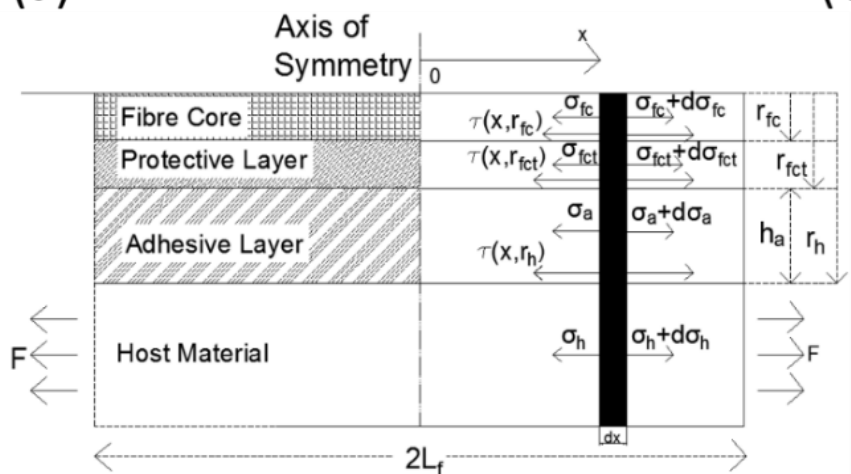

(b) Fibre Core

Fibre Cladding

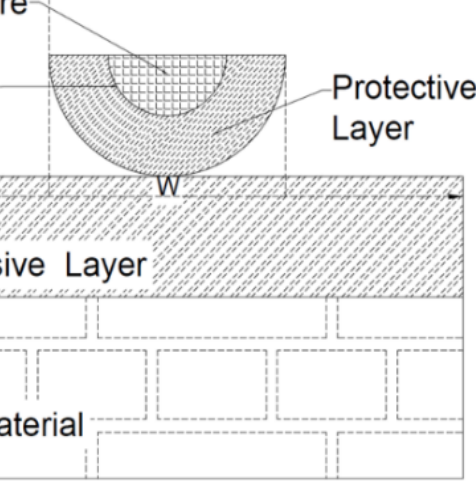

Fig. 1: Stress distribution at various layers of a surface mounted FBG sensor (a) longitudinal view, and (b) cross-sectional view.

(a)

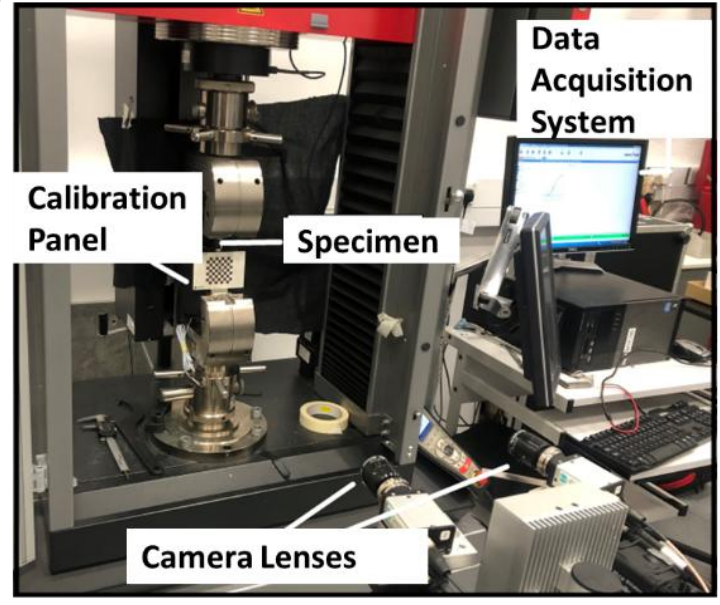

(b)

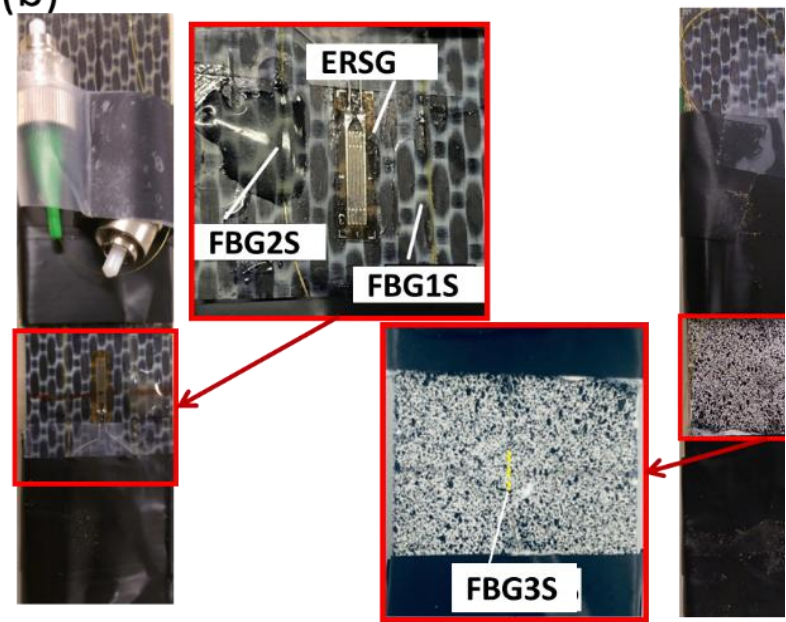

Fig. 2: Test setup and specimen alignment: (a) universal testing machine (b) instrumented carbon PPS specimen. 


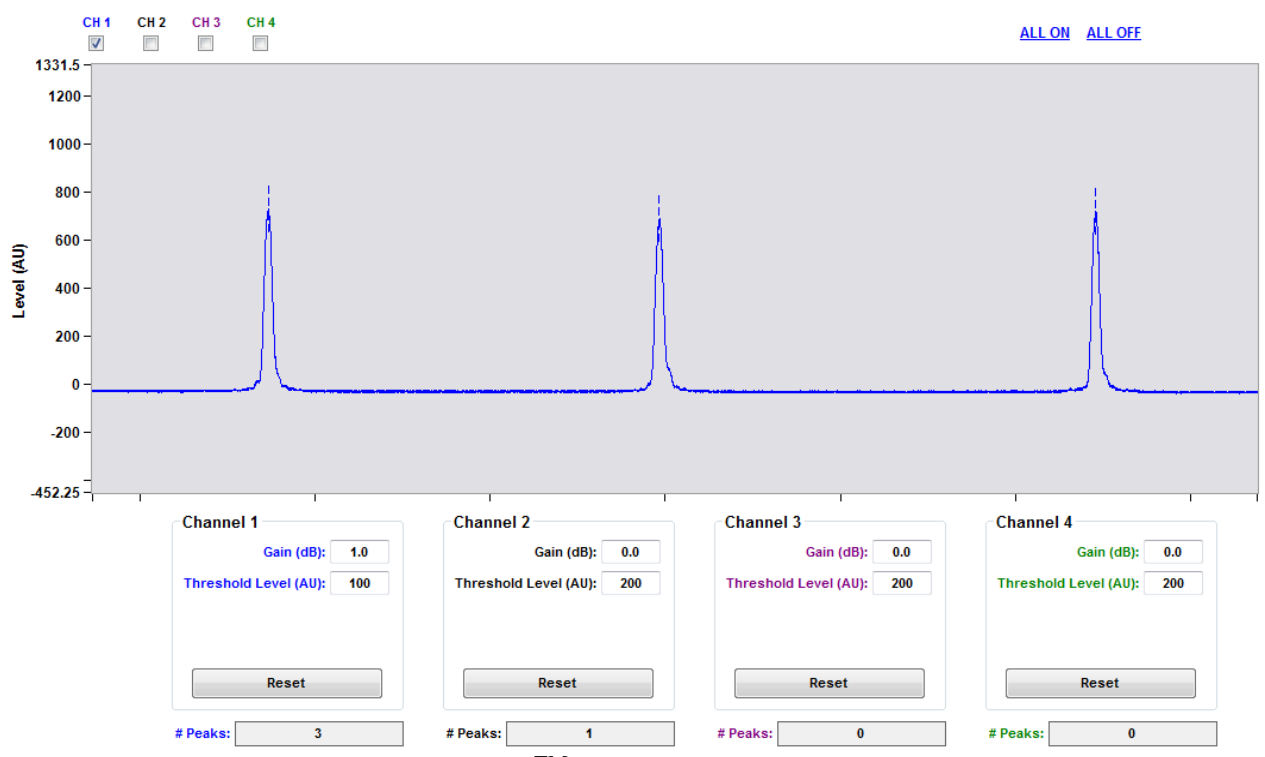

Fig. 3: Reflected spectra obtained from ENLIGH ${ }^{\mathrm{TM}}$ software.
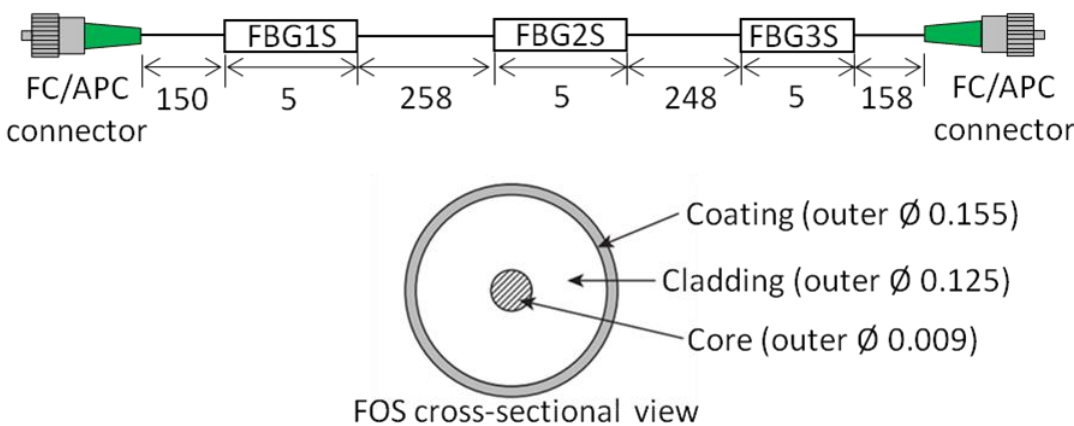

FOS cross-sectional view

FBG2S

ERSG

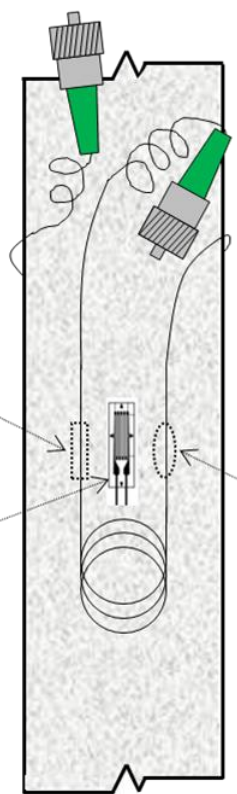

FBG1S

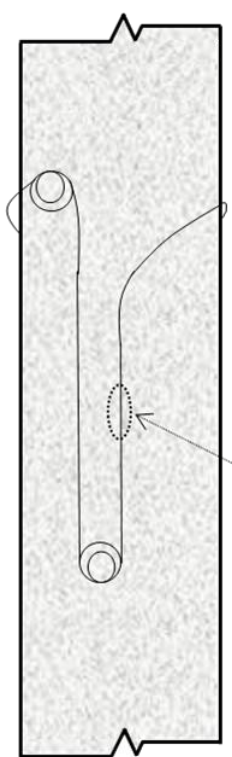

FBG3S

Fig. 4: Schematic depiction of FOS and carbon PPS specimen utilized in the present study (all dimensions are in $\mathrm{mm})$. 

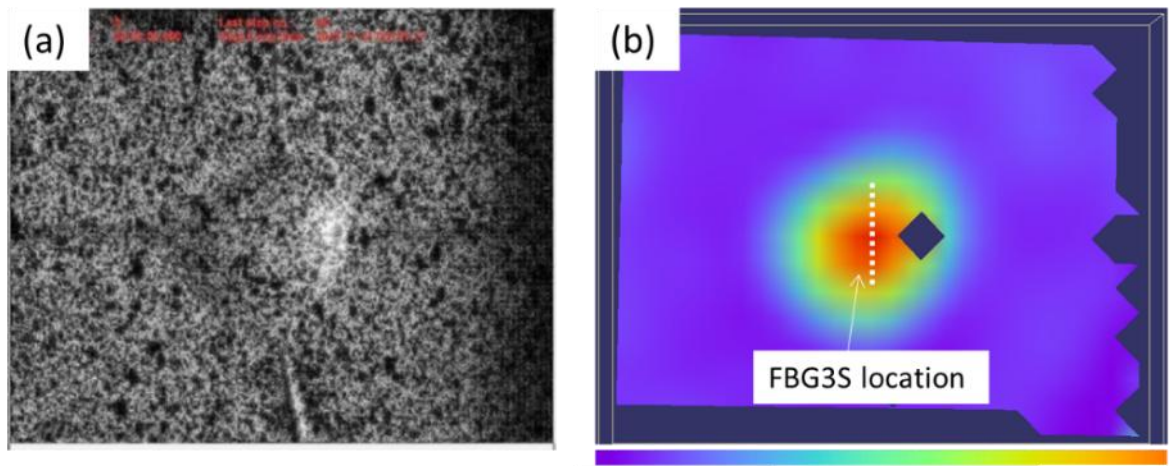

$-0.10 \mathrm{~mm}$

$0.60 \mathrm{~mm}$

Fig. 5: Snapshots from the camera system: (a) speckle pattern over the region of interest, and (b) correlation result for best fit plane.

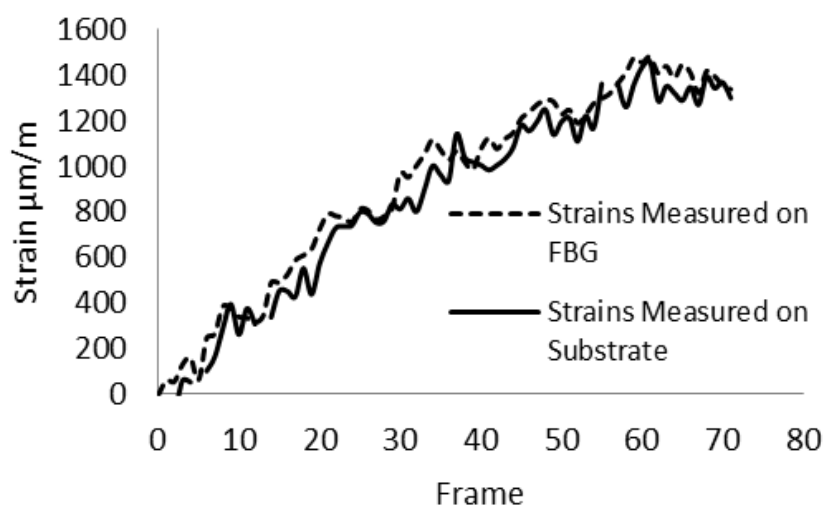

Fig. 6: Comparison of strains on the substrate versus on FBG sensor obtained using DIC. 
(a)

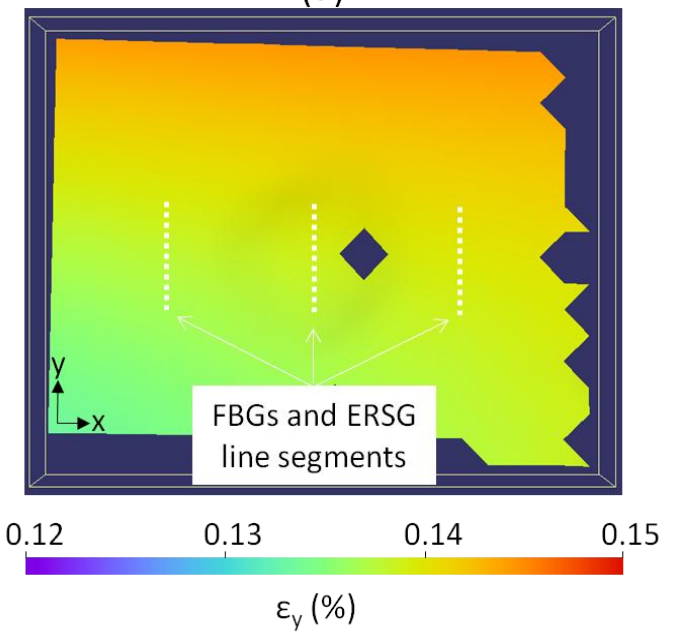

(b)

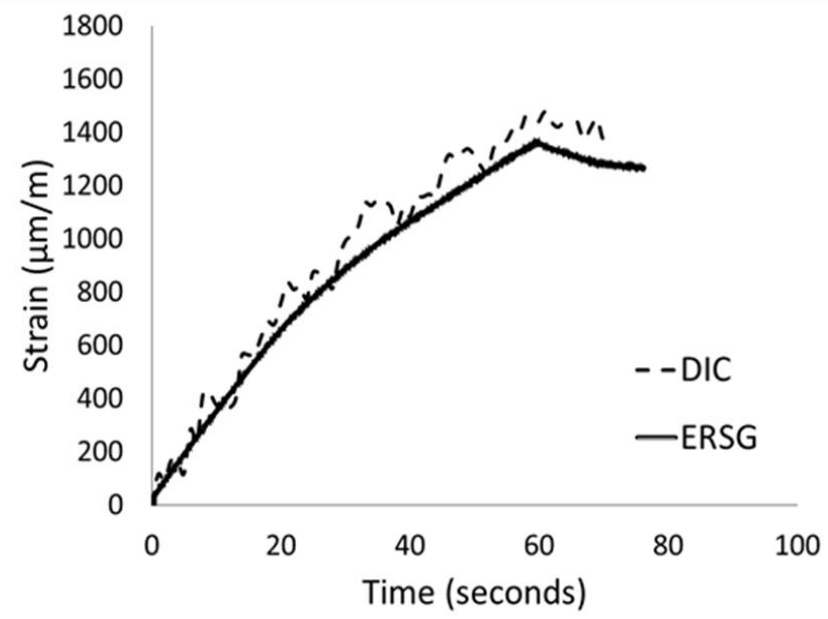

Fig. 7: (a) Longitudinal (y-axis) DIC strain map of specimen's gauge area at maximum load; (b) comparison of strains obtained from DIC and ERSG (indicatively for specimen A).

(a)

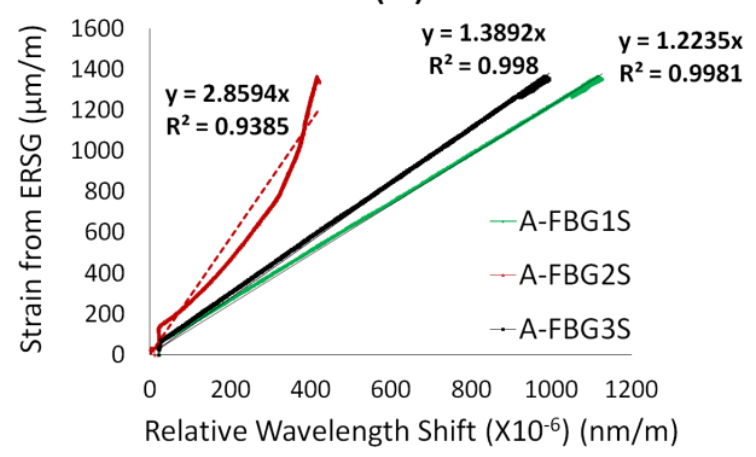

(b)

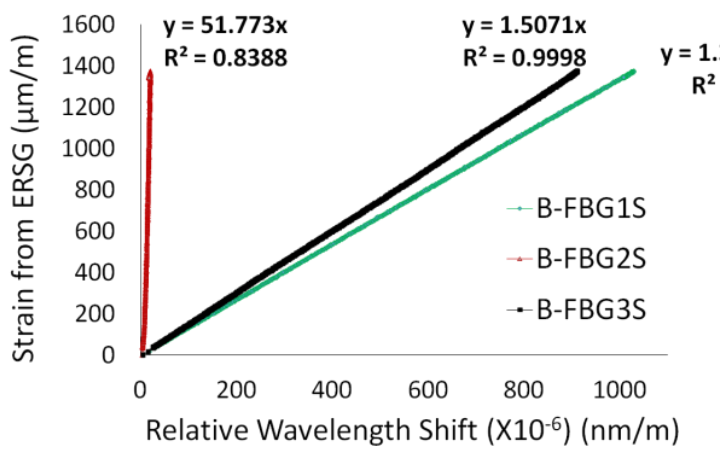

(c)

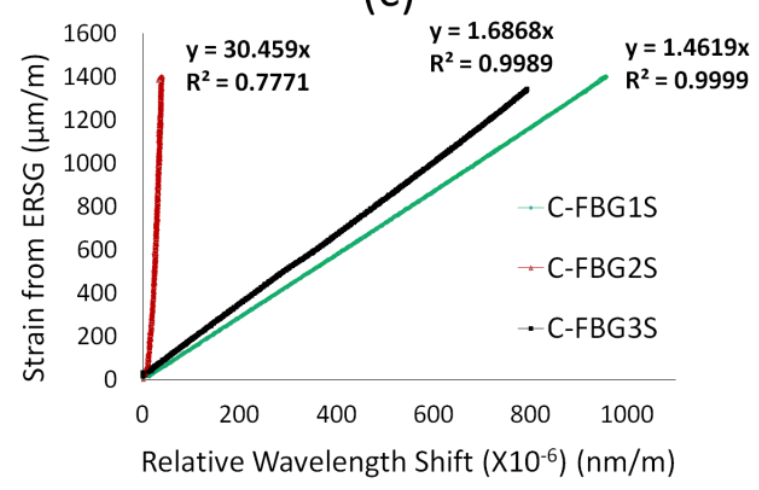

Fig. 8: Relationship between FBG Bragg wavelength and ERSG strain for (a) specimen A, (b) specimen B, and (c) specimen $\mathrm{C}$. 

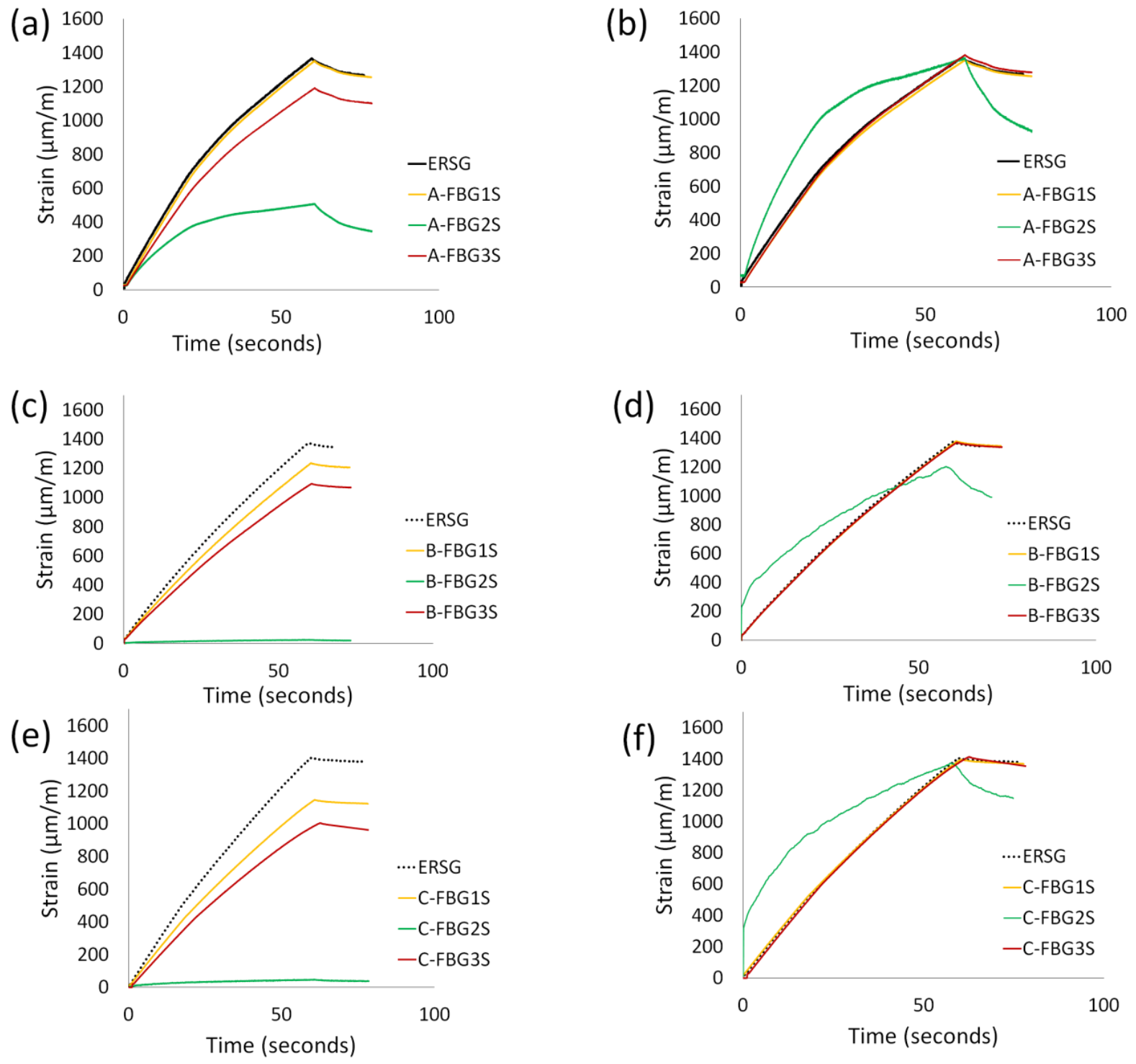

Fig. 9: Comparison of strains obtained from ERSG and FBG sensors for specimen A, B and C: (a), (c), (e) with manufacturer's reported $F_{g}$, and (b), (d), (f) with $F_{g}$ which incorporates correction factors.

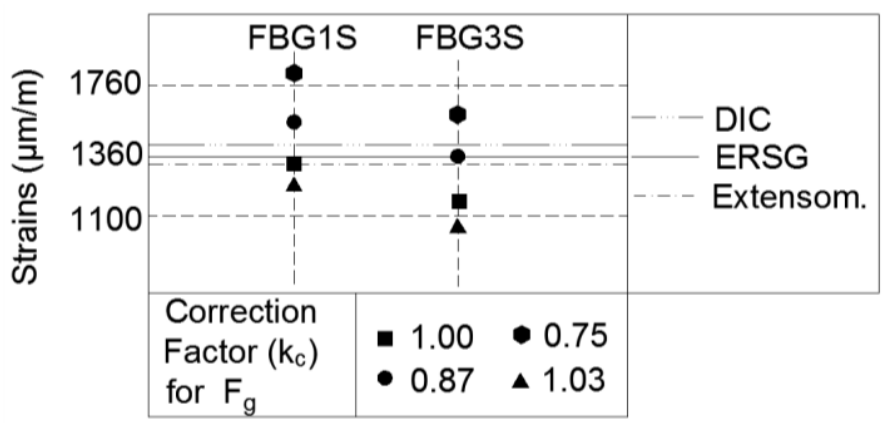

Fig. 10: Responsiveness of FBG measurements based on selected $k_{c}$ values for a representative sample (specimen A). 
(a)

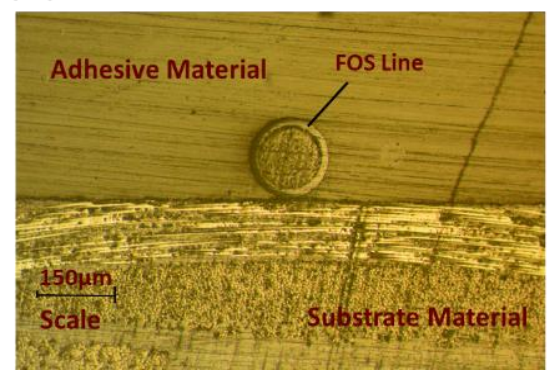

(b)

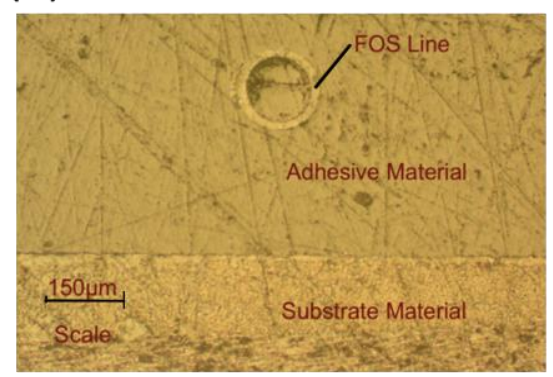

(c)

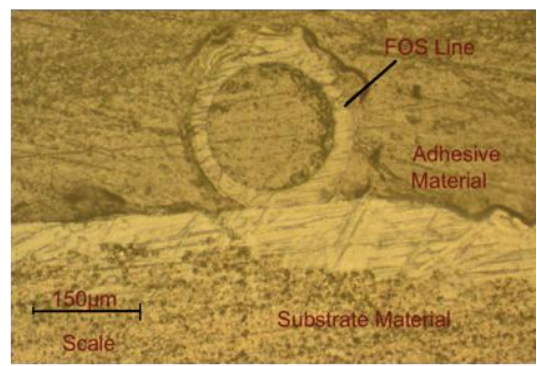

Fig. 11: Microscopic image analysis of indicative carbon PPS specimens for (a) FBG1S, (b) FBG2S and (c) FBG3S.

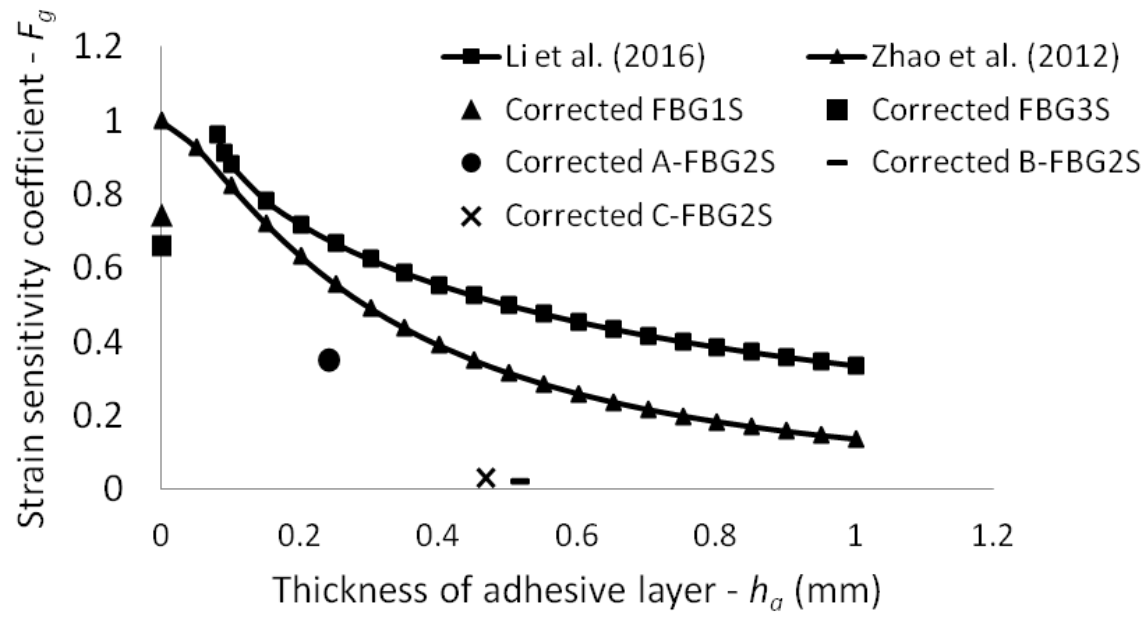

Fig. 12: Comparison of analytical and experimental estimations of $F_{g}$ value. 